\title{
Impact of Hot Pressing Temperature on Medium Density Fiberboard (MDF) Performance
}

\author{
W. Gul, ${ }^{1}$ A. Khan, ${ }^{2}$ and A. Shakoor ${ }^{2}$ \\ ${ }^{1}$ Department of Mechanical Technology, University of Technology, Nowshera, Pakistan \\ ${ }^{2}$ Department of Mechanical Engineering, University of Engineering and Technology, Peshawar, Pakistan \\ Correspondence should be addressed to W. Gul; waheed@uotnowshera.edu.pk
}

Received 20 June 2016; Accepted 13 November 2016; Published 9 January 2017

Academic Editor: Stevulova Nadezda

Copyright ( 2017 W. Gul et al. This is an open access article distributed under the Creative Commons Attribution License, which permits unrestricted use, distribution, and reproduction in any medium, provided the original work is properly cited.

\begin{abstract}
Hot pressing temperature is determined according to the performance of boards, type of glue, and production efficiency of hot press. During hot pressing, the thermal energy has enhanced the plasticity of the fiber and created conditions for the integration of different bonds. The thermal energy will cause the moisture in raw board to vaporize. Temporary heating will expedite the solidification of hot set resin for decreased friction and increased fluidity. The hot pressing temperature usually refers to the temperature of hot pressing plate, but what plays function in actual use is the temperature inside the raw board. This research investigates the performance of MDF with respect to hot pressing temperature. The strength and water resistance of the product are improved with the increase of hot pressing temperature from $140^{\circ} \mathrm{C}$ to $160^{\circ} \mathrm{C}$, the Modulus of Rupture (MOR) is increased by $9.8 \%$, the Internal Bonding (IB) is increased by $33.6 \%$, the water absorption (Wt) is decreased by $38.2 \%$, and the thickness expansion rate $\left(T_{s}\right)$ is decreased by $15.2 \%$.
\end{abstract}

\section{Introduction}

Medium density fiberboard (MDF) is a type of wood sheet produced under optimum pressure and temperature by using wood fiber or other plant fibers as raw materials and applying the urea formaldehyde resin [1]. The density of MDF in production is generally controlled between 690 and $750 \mathrm{Kg} / \mathrm{M}^{3}$. The raw materials used for MDF are firewood from nearby plantations and forest, mango, Ghaz wood (Tamarix aphylla), poplar wood (Populus caspica), eucalypt, wheat straws, rice husk, cotton stalks, Sesbania, sugarcane bagasse, and so forth [2].

The performance index of MDF is divided into three categories, that is, physical performance, mechanical performance, and biological performance [3]. The physical performance mainly includes density, moisture content, and thickness swelling. The mechanical performance mainly includes Internal Bonding, Modulus of Elasticity (MOE), Modulus of Rupture (MOR), and screw holding force (face and side) [4]. The biological performance mainly includes the release of formaldehyde [5].
Figure 1 shows the whole manufacturing process associated with different work stations, that is, material preparation, fiber formation, fiber treatment, mat forming and hot pressing, board treatment, and warehouse. In material preparation section the wood is converted into chips through chipper machine. The chips are then screened to separate the required size [6]. The confirming chips are then transported to chips washer through a belt conveyor with iron remover installed over it. These chips are then washed to improve its quality. These chips are then transferred to fiber separation section. In fiber separation section, the chips are cooked at a temperature of $160-180^{\circ} \mathrm{C} @ 6-8$ bar pressure for about 3-5 min to make it softer. About $1-2 \mathrm{wt} \%$ of paraffin wax is added to the softened chips to make them swelling resistant [7]. The softened chips are then delivered to grinding chamber. In grinding chamber, the materials are mechanically decomposed with the function of water and heat. Pulps are formed. These pulps are then flowing in blow line. While passing through the blow valve, urea formaldehyde resin is added into pulp. After that the pulp in the form of fiber enters into the dryer [8]. In fiber treatment section, the moisture is vaporizing in fiber and 


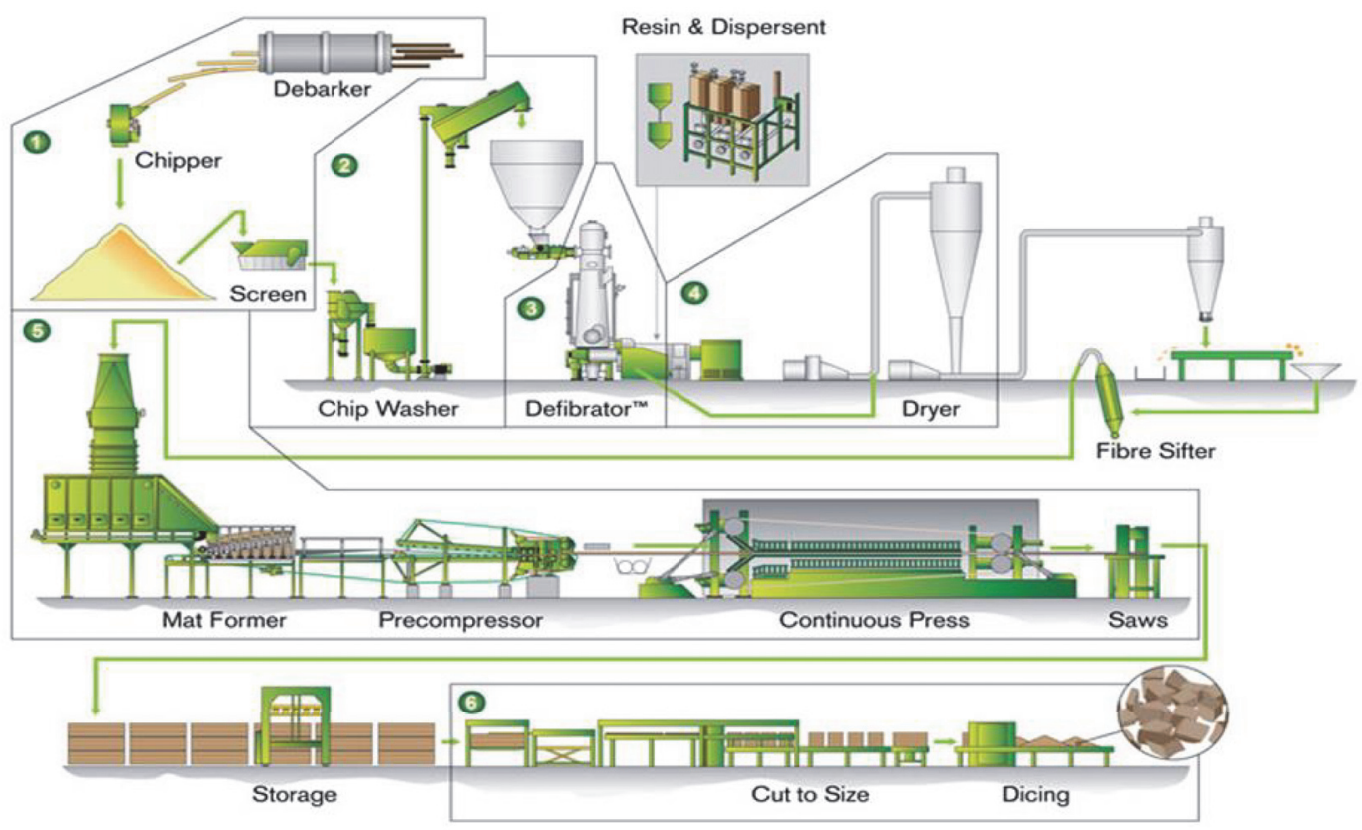

FIGURE 1: MDF manufacturing process (wood force plant).

TABLE 1: Hot press parameters for different thickness of board.

\begin{tabular}{lccccccccccccccccccc}
\hline Th $(\mathrm{mm})$ & $P 1$ & $P 2$ & $P 3$ & $P 4$ & $P 5$ & $P 6$ & $P 7$ & $P 8$ & $P 9$ & $t 0$ & $t 1$ & $t 2$ & $t 3$ & $t 4$ & $t 5$ & $t 6$ & $S 2$ & $T\left({ }^{\circ} \mathrm{C}\right)$ \\
\hline 8 & 170 & 30 & 40 & 90 & 80 & 20 & 12 & 11 & 10 & 55 & 35 & 15 & 15 & 10 & 15 & $S 1+25$ & 170 \\
11 & 170 & 35 & 45 & 90 & 80 & 19 & 12 & 11 & 10 & 80 & 50 & 15 & 15 & 12 & 15 & $S 1+30$ & 170 \\
16 & 190 & 30 & 40 & 160 & 140 & 19 & 12 & 11 & 10 & 100 & 100 & 15 & 20 & 20 & 20 & $S 1+30$ & 190 \\
18 & 190 & 35 & 45 & 170 & 150 & 16 & 12 & 11 & 10 & 120 & 100 & 15 & 20 & 20 & 25 & $S 1+30$ & 190 \\
\hline
\end{tabular}

controls it within the required range. The final moisture content in the fiber is controlled within 8-13 (wt\%). In mat forming section, the fiber is spread evenly into the matting conveyor belt. Under the function of air blow, the mat of specified thickness is formed. The prepress dispels the air out of mat and gives strength to the mat [9].

In board trimming section, the board is cooled and is conveying to the longitudinal and transversal saw for cutting [10]. The dust is removed from sides of board. In sanding section, the board is polished to the required size by removing the extra surface. The board is then inspected and transferred to warehouse [11].

\section{Methodology}

Hot pressing is an important process to manufacture the MDF and plays a decisive role in the product quality and productivity.

Hot pressing refers to a process where the raw board, under the combined function of temperature and pressure, is subjected to moisture evaporation, increase of density, glue solidification, and water proof agent redistribution and the compositions in the raw materials are subjected to a series of physical and chemical changes to form bonding force between the fibers and form the products confirming to quality requirements [12]. Plant fiber material is a micromolecular organic substance complicated in chemical compositions, plus applying of composite resin. Hot pressing process involves not only the change in geometric shape but also such processes as chemical change and physical change [13]. The factors affecting the method include process temperature, type of raw materials, concentrations of ingredients, moisture content, type and performance of resin, and time and pressure of the process. The press cycle and parameters are shown in Table 1 and Figure 2. In Table 1, for $16 \mathrm{~mm}$ board thickness, the whole press cycle time is $275 \mathrm{sec}$ plus position time $(S 1+30)$.

$S 1$ time is the press closing time which is normally 10 seconds. So the total cycle of the hot press for $16 \mathrm{~mm}$ is calculated as 320 seconds. The adjustment is based on the gel time of urea formaldehyde (UF) resin. Similarly, for different thickness and curing of resin, the different parameters are adjusted.

The graph shown in Figure 2 is formed from the hot press parameters mentioned in Table 1.

The main experiment was carried out on $16 \mathrm{~mm}$ board. Four samples of $16 \mathrm{~mm}$ MDF were manufactured with initial parameters as shown in Table 2. 


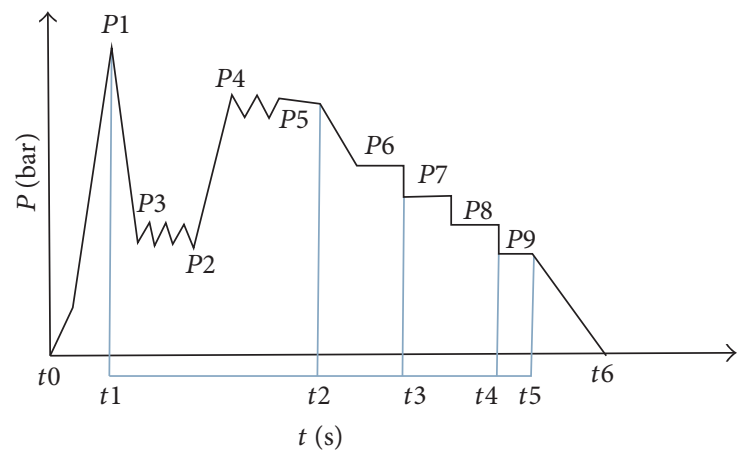

FIGURE 2: Hot press cycle graph.

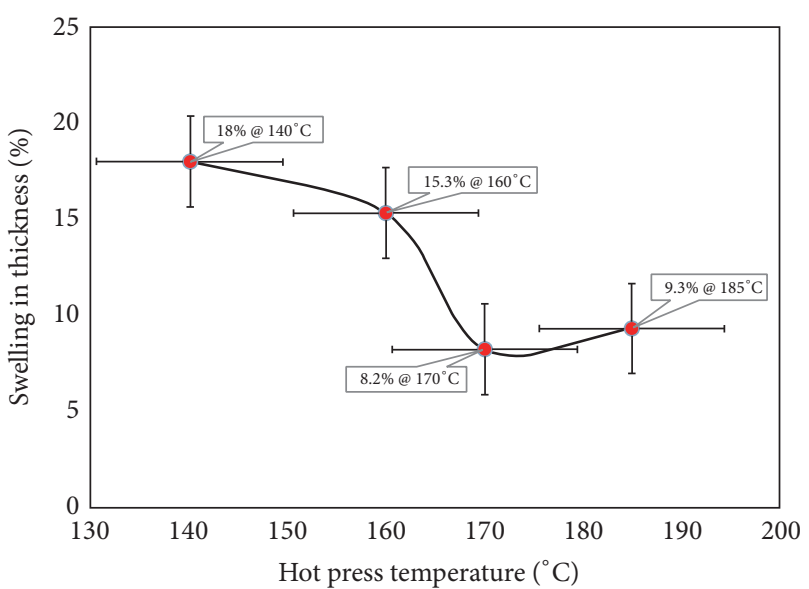

FIGURE 3: Relationship between hot press temperature and swelling in thickness.

\section{Results and Discussions}

Final manufactured MDF properties are concisely summarized in Table 3. The comparative analysis of the well-defined MDF properties, such as water resistance (Wt), swelling in thickness $\left(T_{s}\right)$, Modulus of Rupture (MOR), and Internal Bond (IB), can be accomplished on the basis of temperature variation $[14,15]$. Wt and $T_{s}$ are physical properties of MDF, while MOR and IB are mechanical properties of the formed MDF.

Four samples of MDF are produced at temperature of $140^{\circ} \mathrm{C}, 160^{\circ} \mathrm{C}, 170^{\circ} \mathrm{C}$, and $185^{\circ} \mathrm{C}$. Meanwhile, during manufacturing, the initial parameters, namely, preheating time, UF resin, wax, press timing, and board size, were kept constant [16].

The physical property, swelling in thickness $\left(T_{s}\right)$ of MDF, is consummate with temperature variation ranging from $140^{\circ} \mathrm{C}$ to $185^{\circ} \mathrm{C}$. At $140^{\circ} \mathrm{C}, 160^{\circ} \mathrm{C}, 170^{\circ} \mathrm{C}$, and $185^{\circ} \mathrm{C}$., $T_{s}$ values were recorded as $18 \%, 15.3 \%, 8.2 \%$, and $9.3 \%$, respectively, as shown in Figure 3.

As the temperature increases from $140^{\circ} \mathrm{C}$ to $170^{\circ} \mathrm{C}$, the value of $T_{s}$ decreases from $18 \%$ to $8.2 \%$, but when we increase the temperature from $170^{\circ} \mathrm{C}$ to $180^{\circ} \mathrm{C}, T_{s}$ value is slightly increased from $8.2 \%$ to $9.3 \%$. It means that if we further increase the temperature, $T_{s}$ value will move in ascending

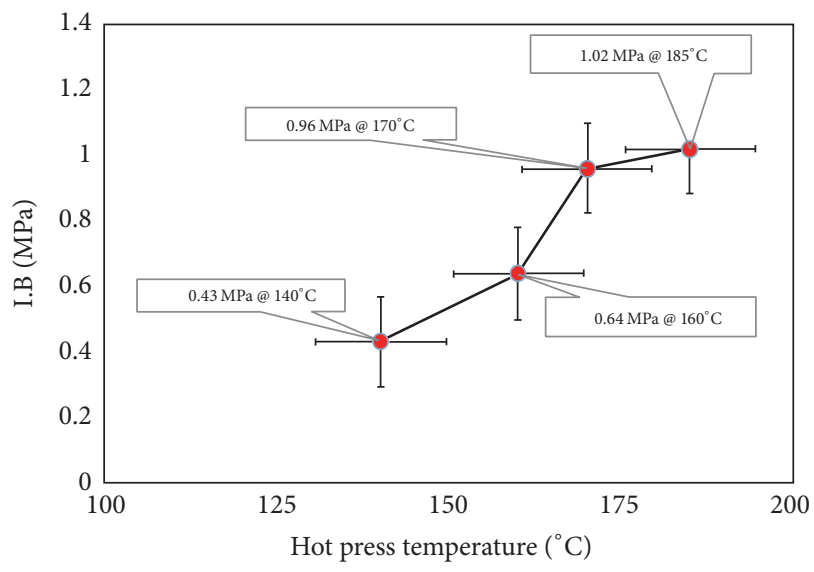

FIGURE 4: Relationship between hot press temperature and Internal Bond (IB).

TABLE 2: The final MDF properties at various temperature.

\begin{tabular}{lcc}
\hline S. number & Parameters & Value \\
\hline 1 & Moisture in fiber & $11 \%$ \\
2 & UF resin & $10 \%$ \\
3 & Hot press plates temperature & $190^{\circ} \mathrm{C}$ \\
4 & Thickness of the board & $16 \mathrm{~mm}$ \\
5 & Press closing time & $40 \mathrm{sec}$ \\
6 & Total press cycle time & $320 \mathrm{sec}$ \\
\hline
\end{tabular}

TABLE 3: The final MDF properties at various temperature.

\begin{tabular}{lccccc}
\hline$T\left({ }^{\circ} \mathrm{C}\right)$ & $\mathrm{IB}(\mathrm{MPa})$ & $\mathrm{Wt}(\%)$ & $\begin{array}{c}\text { Density } \\
\left(\mathrm{gm} / \mathrm{cm}^{3}\right)\end{array}$ & $\begin{array}{c}\mathrm{MOR} \\
(\mathrm{MPa})\end{array}$ & $T_{s}(\%)$ \\
\hline 140 & 0.43 & 29.2 & 0.74 & 29.2 & 18 \\
160 & 0.64 & 18 & 0.72 & 32.3 & 15.3 \\
170 & 0.96 & 17.9 & 0.72 & 31.8 & 8.2 \\
185 & 1.02 & 22 & 0.73 & 30 & 9.3 \\
\hline
\end{tabular}

order and the strength of MDF will be reduced. The best and acceptable temperature range for $\mathrm{MDF}$ is from $170^{\circ} \mathrm{C}$ to $180^{\circ} \mathrm{C}$. This is the optimum medium range of temperature. Calculated $T_{s}$ values also depend upon the nature of curing of resin used as binder and hot press time [17, 18]. Low temperature and high temperature are strictly prohibited for MDF in normal case of resin curing. Meanwhile $T_{s}$ value according to standard (EN-317) is $<12 \%$.

In record of the manufactured MDF samples, the experimental values of mechanical adhesive property, that is, Internal Bond (IB), is ranging from 0.43 $\mathrm{MPa}$ to $1.02 \mathrm{MPa}$ for a temperature range from $140^{\circ} \mathrm{C}$ to $185^{\circ} \mathrm{C}$ as shown in Figure 4 .

The IB value at low temperature $\left(140^{\circ} \mathrm{C}\right)$ is $0.43 \mathrm{MPa}$, while for a $16 \mathrm{~mm}$ MDF the IB value is standardized (EN-319) as $0.6 \mathrm{MPa}$. Hence, at $140^{\circ} \mathrm{C}$, the MDF will have a very poor strength. But when the temperature is exceeded from $140^{\circ} \mathrm{C}$ to $160^{\circ} \mathrm{C}$, the $\mathrm{IB}$ value reaches $0.64 \mathrm{MPa}$. So at $160^{\circ} \mathrm{C}$, the $\mathrm{MDF}$ follows the standard value and strength. If we further increase the temperature from $160^{\circ} \mathrm{C}$ to $170^{\circ} \mathrm{C}$, a direct relation is set up between temperature and IB and the IB value continuously 


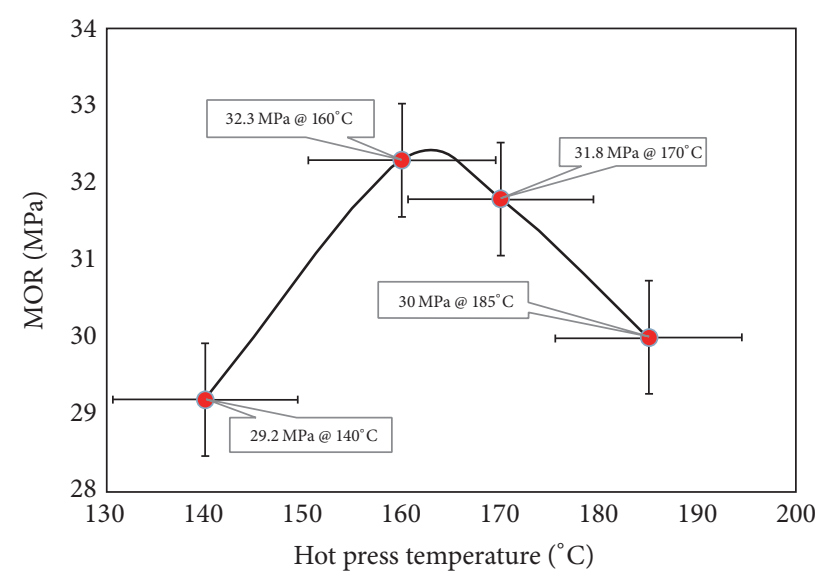

FIGURE 5: Relationship between hot press temperature and Modulus of Rupture (MOR).

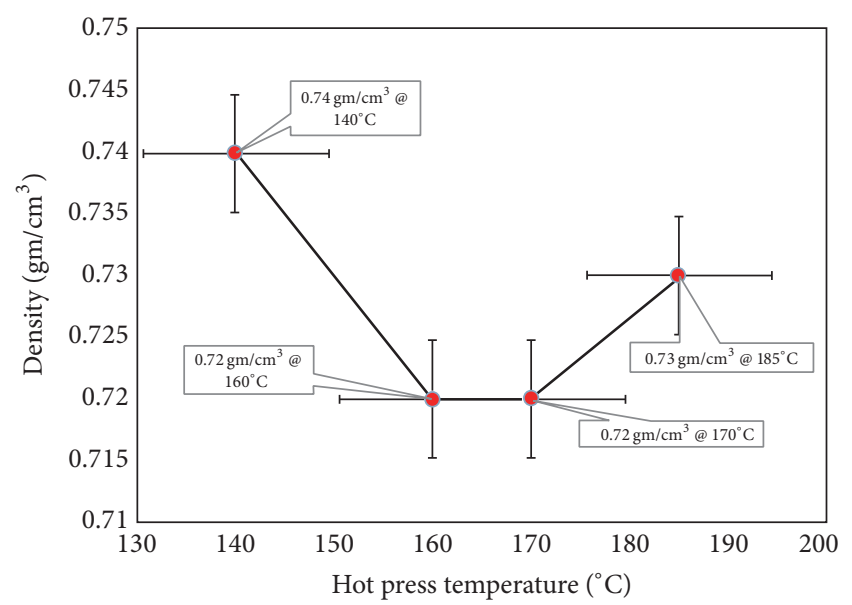

FIGURE 6: Relationship between hot press temperature and density of MDF.

increases [19]. At maximum value of temperature $\left(185^{\circ} \mathrm{C}\right)$, the IB value $1.02 \mathrm{MPa}$ is obtained. But if we further increase the temperature, the surface and core layer may lead to a high temperature difference and ultimately the MDF may become brittle.

The samples of MDF are also tested for a very important mechanical property, namely, MOR [20]. The experimental values of MOR are calculated as $29.2 \mathrm{MPa}, 32.2 \mathrm{MPa}$, $31.8 \mathrm{MPa}$, and $30 \mathrm{MPa}$ for temperature of $140^{\circ} \mathrm{C}, 160^{\circ} \mathrm{C}, 170^{\circ} \mathrm{C}$, and $185^{\circ} \mathrm{C}$, respectively, as shown in Figure 5. Even at low temperature $\left(140^{\circ} \mathrm{C}\right)$, the $\mathrm{MOR}$ value is very close to standard (EN-310) value ( $\geq 30 \mathrm{MPa})$. At $160^{\circ} \mathrm{C}$, the $\mathrm{MOR}$ value is at its peak $(32.3 \mathrm{MPa})$. However, if we further increase the temperature from $160^{\circ} \mathrm{C}$ to $185^{\circ} \mathrm{C}$, the MOR behaves in reverse manner.

Figure 6 demonstrates the effect of temperature over the density. The physical property, density of MDF, is consummate with temperature variation ranging from $140^{\circ} \mathrm{C}$ to $185^{\circ} \mathrm{C}$. At $140^{\circ} \mathrm{C}, 160^{\circ} \mathrm{C}, 170^{\circ} \mathrm{C}$, and $185^{\circ} \mathrm{C}$, the values of density were recorded as $0.74 \mathrm{~g} / \mathrm{cm}^{3}, 0.72 \mathrm{~g} / \mathrm{cm}^{3}, 0.72 \mathrm{~g} / \mathrm{cm}^{3}$,

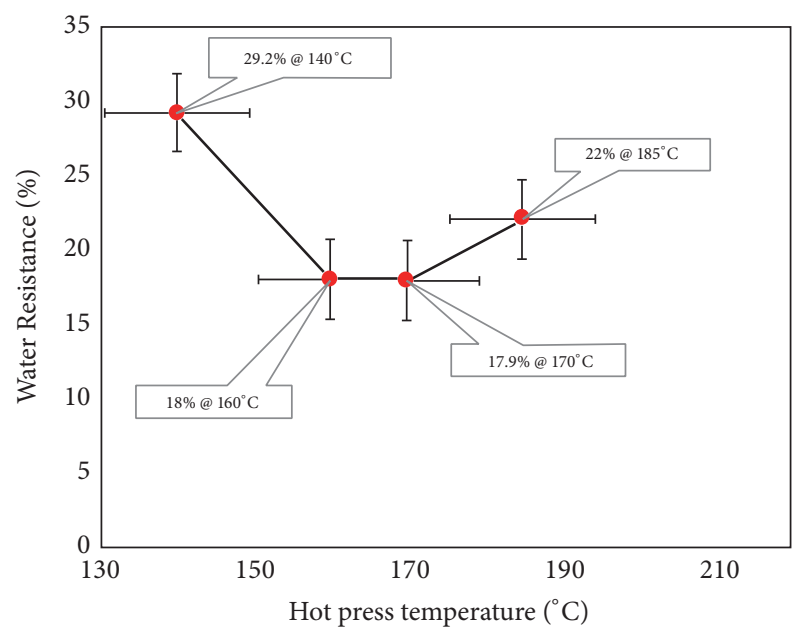

FIgURE 7: Relationship between hot press temperature and water resistance of MDF.

and $0.73 \mathrm{~g} / \mathrm{cm}^{3}$. At low temperature, the density value is maximum, that is, $0.74 \mathrm{~g} / \mathrm{cm}^{3}$. If we increase the temperature from $140^{\circ} \mathrm{C}$ to $160^{\circ} \mathrm{C}$, the density value dropped from $0.74 \mathrm{~g} / \mathrm{cm}^{3}$ to $0.72 \mathrm{~g} / \mathrm{cm}^{3}$. If we further increase the temperature from $160^{\circ} \mathrm{C}$ to $170^{\circ} \mathrm{C}$, the value of density remains constant. However, when temperature increases from $170^{\circ} \mathrm{C}$ to $185^{\circ} \mathrm{C}$, the density is also increased from $0.72 \mathrm{gm} / \mathrm{cm}^{3}$ to $0.73 \mathrm{gm} / \mathrm{cm}^{3}$.

For systematic judgment of the MDF property, the hot press temperature values are drawn against water resistance. The water resistance property shows dramatic behavior against temperature and the strength for MDF is fluctuating. At temperature of $140^{\circ} \mathrm{C}$, the water resistance value is $29.2 \%$, as shown in Figure 7. However, when the temperature increases from $140^{\circ} \mathrm{C}$ to $160^{\circ} \mathrm{C}$, the water resistance value decreases from $29.2 \%$ to $18 \%$. At $160^{\circ} \mathrm{C}$, the water resistance value is ideal and the strength of MDF is at its peak. But as the temperature further increases from $160^{\circ} \mathrm{C}$ to $170^{\circ} \mathrm{C}$, the water resistance value slightly decreases from $18 \%$ to $17.9 \%$. However, at maximum recorded temperature, its value again increases. This fluctuating behavior of water resistance is the high temperature difference between the surface and core layer [21].

\section{Conclusions}

The MDF is of medium density, the moisture content of fibers in raw board is not high, and the raw board is thick but loose and poor in heat conductivity. The heating is mostly by means of contact transfer. Therefore, the temperature difference between the surface and core of the raw board is high. To ensure full solidification temperature of different glues, usually, $160-180^{\circ} \mathrm{C}$ is selected. The selection of temperature also depends on other factors such as the raw materials, type of trees, and moisture content in raw board, glue property, thickness of raw board, heating method, heating time, and pressure. It is shown in above results that the performance of MDF is closely related to hot pressing temperature. The strength and water resistance of the product are improved 
with the increase of hot pressing temperature from $140^{\circ} \mathrm{C}$ to $160^{\circ} \mathrm{C}$; the MOR will be increased by $9.8 \%$, the IB bond will be increased by $33.6 \%$, the water absorption will be decreased by $38.2 \%$, and the thickness expansion rate will be decreased by $15.2 \%$. This is because, with the rise of hot pressing temperature, the lapse of the temperature on the surface and core layer of the raw board will be increased, the thermal conduction will be expedited, and the core layer temperature will rise quickly. So that the glue can flow better and be evenly distributed between the fibers; thus it can be thoroughly solidified. In addition, the rise of temperature may reinforce the degradation of chemical consumption in fiber thus to enhance the activity of fiber for easy bond between the fibers. But if the temperature continues to rise up to $185^{\circ} \mathrm{C}$, the strength and water resistance of board may be decreased, which might be caused by degradation and brittleness of the resin. The determination of hot pressing temperature is related to the thickness and density of product. To produce the product with a density of $0.6 \mathrm{gm} / \mathrm{cm}^{3}$ and thickness of $11 \mathrm{~mm}$, the temperature difference between the surface and core layer of the raw board may be high up to $40-$ $60^{\circ} \mathrm{C}$. A higher temperature difference will cause difficulty in production of thick boards. This is because the surface fiber of raw board is in direct contact with the hot pressing plate and the glue in the surface fiber will be solidified in the short time. However, it will take longer time for the core layer to reach this solidifying temperature, so that this will surely extend the hot pressing cycle. If we increase the temperature to enhance the heat transfer effect, this might cause the degradation of surface fiber and oversolidifying of the glue. Therefore, a lot of new technologies are being developed for the technology of heating medium. For example, when carrying out contact heating of the raw boards, addition of high-frequency heating and adoption of spray cooking can play a positive role in quickly increasing the temperature of raw boards, shortening the pressurizing time, and improving the performance of the products.

\section{Competing Interests}

The authors declare that there are no competing interests regarding the publication of this paper.

\section{References}

[1] A. Ashori, A. Nourbakhsh, and A. Karegarfard, "Properties of medium density fiberboard based on bagasse fibers," Journal of Composite Materials, vol. 43, no. 18, pp. 1927-1934, 2009.

[2] N. Ayrilmis, S. Jarusombuti, V. Fueangvivat, and P. Bauchongkol, "Effects of thermal treatment of rubberwood fibres on physical and mechanical properties of medium density fibreboard," Journal of Tropical Forest Science, vol. 23, no. 1, pp. $10-16,2011$.

[3] W. Gul, A. Khan, and A. Shakoor, "Improving physical and mechanical properties of medium density fiberboard," in Proceedings of the 4th International Conference on Aerospace Science and Engineering (ICASE '15), pp. 57-62, Islamabad, Pakistan, September 2015.
[4] W. Gul, A. Khan, and A. Shakoor, "Investigation and analysis of Tamarix aphylla (Ghaz wood) and Populus caspica (poplar wood) used as raw materials for manufacturing of Medium Density Fiberboard (MDF)," Journal of Advanced Materials Science, 2016.

[5] J. J. Balatinecz and D. E. Kretschmann, "Properties and Utilization of Poplar Wood," in Poplar Culture in North America, part A, pp. 277-291, 2001.

[6] S. B. Halvarsson, H. Edlund, and M. Norgren, "Wheat straw as raw material for manufacture of straw Mdf," BioResources, vol. 5, no. 2, pp. 1215-1231, 2010.

[7] Z. Ibrahim, A. Abdul Aziz, R. Ramli, W. H. WanHassan, and N. H. Zainal, "Optimum parameters for the production of MDF using $100 \%$ oil palm trunks," MPOB Information Series 566, 2006.

[8] Ü. Büyüksari, S. Hiziroglu, H. Akkılıç, and N. Ayrılmış, "Mechanical and physical properties of medium density fiberboard panels laminated with thermally compressed veneer," Composites Part B: Engineering, vol. 43, no. 2, pp. 110-114, 2012.

[9] A. Kargarfard, A. Nourbakhsh, and H. Hosseinkhani, "Investigation on Medium Density Fiberboard (MDF) properties produced from horn beam wood," Pajouhesh-va-Sazandegi, vol. 20, no. 1, pp. 25-31, 2007.

[10] A. Kargarfard and A. Jahan-Latibari, "The performance of corn and cotton stalks for medium density fiberboard production," BioResources, vol. 6, no. 2, pp. 1147-1157, 2011.

[11] S. Lee, T. F. Shupe, and C. Y. Hse, "Mechanical and physical properties of agro-based fiberboard," Holz als Roh-und Werkstoff, vol. 64, no. 1, pp. 74-79, 2006.

[12] L. M. H. Carvalho, M. R. N. Costa, and C. A. V. Costa, "A global model for the hot-pressing of MDF," Wood Science and Technology, vol. 37, no. 3-4, pp. 241-258, 2003.

[13] K. Li, "On determining density and specific heat of New Zealand medium density fibreboard," Procedia Engineering, vol. 62, pp. 769-177, 2013.

[14] X. Li, Physical, Chemical, and Mechanical Properties of Bamboo and Its Utilization Potential for Fiberboard Manufacturing, Beijing Forestry University, Beijing, China, 2004.

[15] G. Mantanis and J. Berns, "Strawboards bonded with urea formaldehyde resins," in Proceedings of the 35th International Particleboard/Composite Materials Symposium Proceedings, pp. 137-144, April 2001.

[16] B. Mohebby, F. Ilbeighi, and S. Kazemi-Najafi, "Influence of hydrothermal modification of fibers on some physical and mechanical properties of medium density fiberboard (MDF)," Holz als Roh- und Werkstoff, vol. 66, no. 3, pp. 213-218, 2008.

[17] M. Nazerian, A. Dalirzadeh, and S. R. Farrokhpayam, "Use of almond shell powder in modification of the physical and mechanical properties of medium density fiberboard," BioResources, vol. 10, no. 1, pp. 169-181, 2014.

[18] R. Ramli, S. Shaler, and M. A. Jamaludin, "Properties of medium density fibreboard from oil palm empty fruit bunch fibre," Journal of Oil Palm Research, vol. 14, no. 2, pp. 34-40, 2002.

[19] J. Valenzuela, E. Von Leyser, A. Pizzi, C. Westermeyer, and B. Gorrini, "Industrial production of pine tannin-bonded particleboard and MDF," European Journal of Wood and Wood Products, vol. 70, no. 5, pp. 735-740, 2012. 
[20] J. E. Winandy and A. M. Krzysik, "Thermal degradation of wood fibers during hot-pressing of MDF composites: part I. Relative effects and benefits of thermal exposure," Wood and Fiber Science, vol. 39, no. 3, pp. 450-461, 2007.

[21] W. Xu, "Influence of vertical density distribution on bending modulus of elasticity of wood composite panels: a theoretical consideration," Wood and Fiber Science, vol. 31, no. 3, pp. 277282, 1999. 

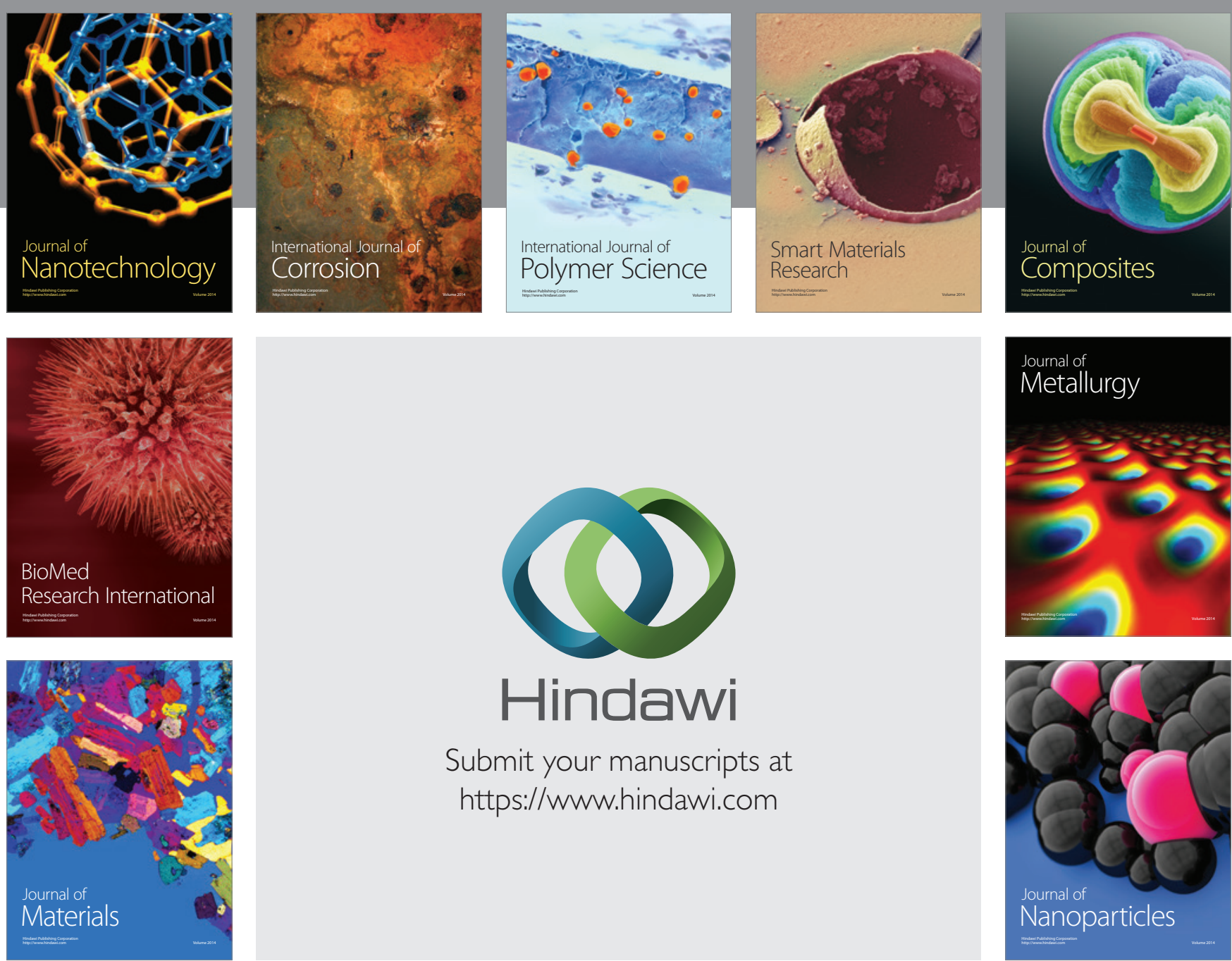

\section{Hindawi}

Submit your manuscripts at

https://www.hindawi.com

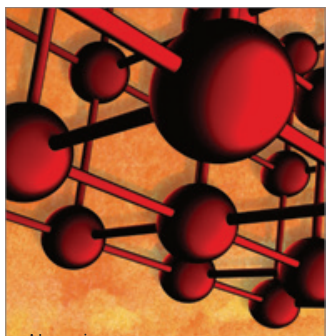

Materials Science and Engineering
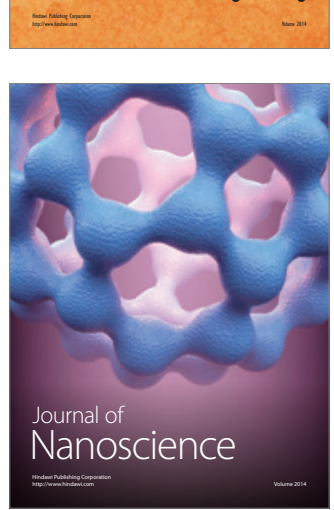
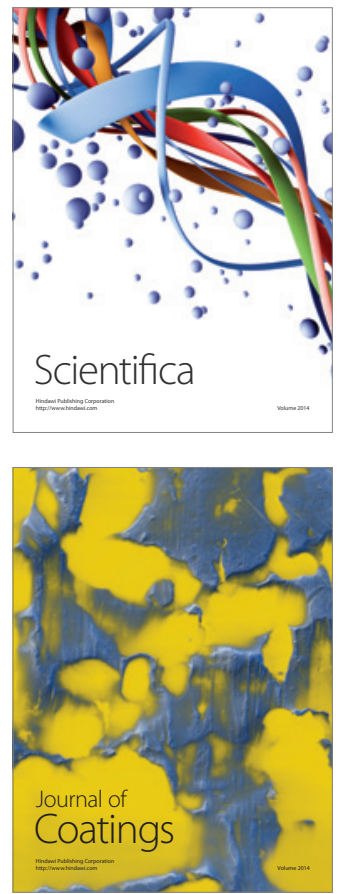
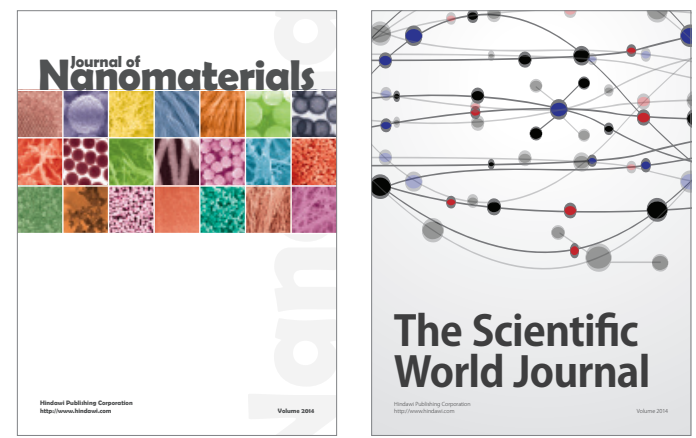

The Scientific World Journal
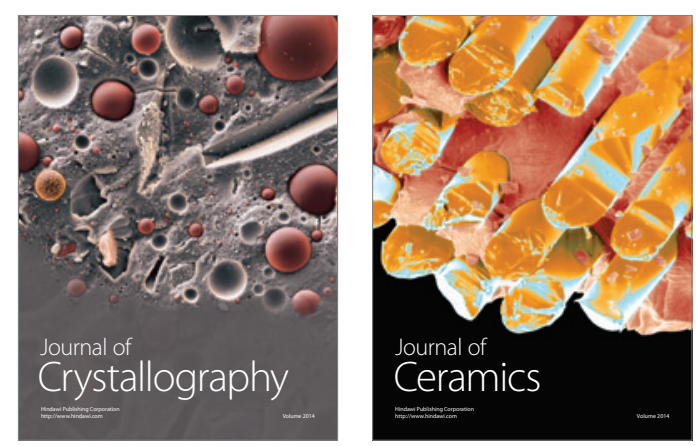
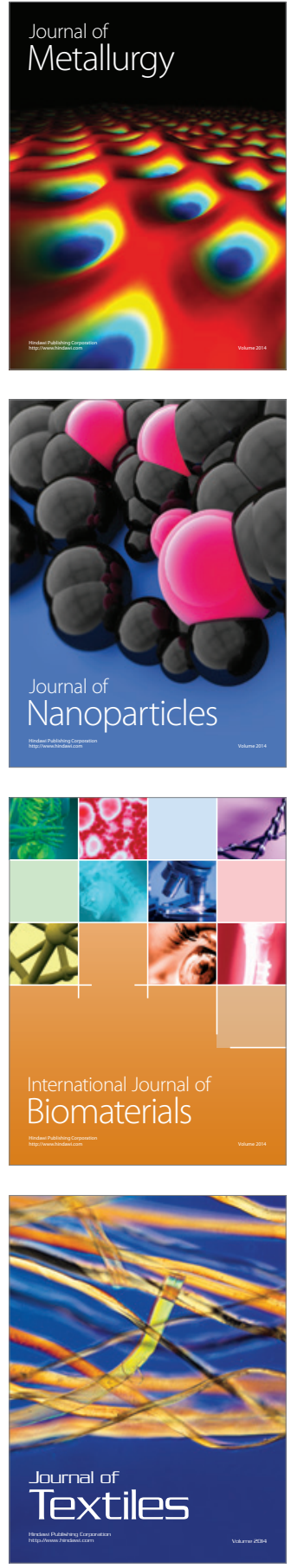